\title{
Perovskite Solar Cells in Space: Evaluation of Perovskite Solar Cell Hole Transport Material in Space Environment*
}

\author{
Izrael Zenar C. Bautista, ${ }^{1)}$ Shuzhang Yang, ${ }^{2)}$ Aekjira KuyYaKanont, ${ }^{1)}$ Minoru IwatA, ${ }^{1)}$ Tingli MA, ${ }^{2)}$ and Mengu ChO ${ }^{1) \dagger}$ \\ ${ }^{1)}$ Laboratory of Lean Satellite Enterprises and In-Orbit Experiments, Kyushu Institute of Technology, Kitakyushu, Fukuoka 804-8550, Japan \\ ${ }^{2)}$ Graduate School of Life and Systems Engineering, Kyushu Institute of Technology, Kitakyushu, Fukuoka 808-0196, Japan
}

Majority of spacecrafts rely on solar power as the main source of energy. The search for a lightweight and costefficient energy source with high power conversion efficiency (PCE) led to the development of organic-inorganic metal halide Perovskite solar cells (PSCs). In this paper, the performance of PSCs with different hole-transport material (HTM) prepared for in-orbit demonstration mission onboard CubeSats are compared under simulated space environment such as thermal cycling stress, high-vacuum, UV radiation and vibration. Results show that even though organic and inorganic HTM display superior initial PCE, Carbon HTM PSCs trumps them in terms of stability and is more practical for use in space. The paper also discusses the satellite mission and developed hardware for the first demonstration of Perovskite solar cells on-board a satellite to gather in-orbit information on the performance of Perovskite solar cells in low-earth orbit and how the ground test results would be verified.

Key Words: Energy, Nanosatellite, Perovskite Solar Cell, In-orbit Demonstration

\section{Acronyms}

PCE: Power conversion efficiency

PSC: Perovskite solar cell

HTM: Hole transport material

UV: Ultraviolet

CTL: Charge transport layer

ETL: Electron transport layer

HTL: Hole transport layer

DSSC: Dye sensitized solar cell

\section{Introduction}

More than 60 years ago, the first satellite powered by solar cells, Vanguard 1, was launched into orbit marking the first use of solar cells as energy source for spacecrafts. ${ }^{1)}$ Using silicon solar cells with power conversion efficiency of approximately $10 \%$, the satellite was able to operate for 6 years. ${ }^{2}$ At present, multi-junction solar cells are being used for their higher efficiency, power density and lifespan under space radiation compared to silicon solar cells. ${ }^{3)}$

The emergence of the organic-inorganic metal halide perovskite as a solar cell material in $\left.2009,{ }^{4}\right)$ has opened new avenues for research, with record efficiency of $25.5 \%$ for single junction type, ${ }^{5)}$ and with theoretical maximum conversion efficiency of $38 \%$ in a tandem architecture. ${ }^{6)}$ Perovskite solar cells have a distinct advantage over multi-junction solar cells due to its higher power density, cheaper production cost and higher tolerance to radiation. ${ }^{7-9)}$ The cost of production is further driven down by the compatibility of PSC to be

(C) 2022 The Japan Society for Aeronautical and Space Sciences

*Received 25 December 2020; final revision received 20 July 2021; accepted for publication 6 September 2021.

†Corresponding author, cho@ele.kyutech.ac.jp
Table 1. Comparison of cost per watt of solar cell technology used in space and Perovskite.

\begin{tabular}{llc}
\hline & Price per watt $(\$ / W)$ & Power density $(\mathrm{W} / \mathrm{kg})$ \\
\hline Triple junction & $286.9^{15}$ & 3,600 \\
Perovskite & $0.127^{16)}$ & $23,000^{17)}$ \\
\hline
\end{tabular}

manufactured in flexible substrates which allows very high throughput roll-to-roll manufacturing process. In Ref. 8), the manufacturing cost and market potential of roll-to-roll manufacturing processes are analysed. The main barrier for low-cost mass production were the high cost of HTM materials, screen printing process of back-end electrode and transparent front conductor (ITO). Advancement in these three factors to lower their costs is projected to result a manufacturing cost of only US\$37/ $\mathrm{m}^{2} \pm 30 \%$. Table 1 shows how much better PSC is compared to the triple junction solar cell commonly used in space. Not only is it cheaper by more than three orders of magnitude, PSC is also six times denser in terms of power. These advantages though, come with disadvantages such as instability, hysteresis and toxicity which hinders commercialization of PSCs. A major factor for instability and short lifespan is the exposure to oxygen and moisture which are both absent in space. ${ }^{10,11)}$ A recent paper by Yang et al. outlined the potential of PSCs in space and the challenges for its implementation. ${ }^{12)}$ Several papers are also published about the performance of PSCs under various environmental conditions that contribute to the degradation of its performance. ${ }^{9,13,14)}$

There are three classifications for HTM: Organic, Inorganic and Carbonaceous material. The performance of PSCs not only depend on the light absorbing material, but also on the charge transporting layers (CTL). In the case of hole transport layers (HTL), it acts as a physical and energy bar- 
rier between the perovskite layer and the other electron transport layer (ETL). They also improve the efficiency of transporting holes because of their high hole mobility and because their energy level matches with HTM electrode. The degradation of the perovskite layer is also prevented by HTLs and prevents charge recombination which improves device performance. ${ }^{18)}$ Reference 19) made a comprehensive review on various HTMs used in PSCs based on published research articles. In this review article, they made a detailed comparison of the HTMs based on cost and device performance (efficiency and stability). According to the review, a large number of reports use organic HTMs such as SpiroOMeTAD (2,2',7,70-Tetrakis(N,N-di-(4-methoxyphenyl)amino)-9,9'-spirobifluorene), because of several properties such as solubility, ionization potential, absorption spectrum and solid-state morphology. ${ }^{20)}$ This results to easy device fabrication with high open-circuit voltage and achieve high efficiencies. $^{21)}$

Reference 22) first demonstrated the use of SpiroOMeTAD as HTM in 1998 in dye sensitized solar cells (DSSCs) and achieved a PCE of $2.56 \%$ in a laboratory. The drawback is the high cost and instability of organic HTMs. ${ }^{23)}$ This led researchers to look for inexpensive, abundant, nontoxic and low energy extensive materials such as inorganic HTMs. Cuprous thiocyanate or CuSCN as inorganic HTM was first demonstrated by Ref. 24) and achieved PCE of $6.4 \%$. Inorganic HTMs were able to deliver in terms of cost efficiency and stability because they have wider band gap, high conductivity and also prevented the device from exposure to surrounding environment because of its hydrophobic property. ${ }^{25,26)}$ Unfortunately, the power conversion efficiency is not as good as organic HTMs. Carbon materials were initially identified as good replacement to gold as back electrode, because of its good conductivity and low cost. It was also identified as a potential material to replace HTM because it has a work function value $\sim 5.0 \mathrm{eV}$. The lower cost, abundancy and its capability to be both HTM and electrode made carbon HTM an ideal candidate for further research as hole-conductor for PSCs. ${ }^{27,28)}$ Table 2 shows a comparison of the price and energy level of the HTM materials used. The energy level of the three HTMs used in this study matches the energy level of Perovskite material.

Reference 30) attached Perovskite cells in a weather balloon which reached a height of $32 \mathrm{~km}$ for 3 hours and recorded the performance of the cells every 20 seconds and compared the characteristics of the cells before and after flight. Their results showed most of the devices stopped working after the flight due to encapsulation failure which lead to degradation of the active layer and the charge transport layers. The main conclusion from their study is the ex-

Table 2. Comparison of HTMs used.

\begin{tabular}{lcl}
\hline & Price/gram $(\$)^{29)}$ & Energy level $(\mathrm{eV})^{19)}$ \\
\hline Spiro-OMeTAD & 347.000 & $-5.3 \sim-2.3$ \\
CuSCN & 1.652 & $-5.3 \sim-1.5$ \\
Carbon & 0.915 & -5.0 \\
\hline
\end{tabular}

treme temperature greatly affects the performance of the PSC and focused for further research.

A more recent article published in Joule by Ref. 31) attached Perovskite solar cells in a suborbital rocket reaching a height of $240 \mathrm{~km}$ for a total measurement time of 6 minutes. The measurement done under varying light intensity has shown efficient performance of up to $14 \mathrm{~mW} / \mathrm{cm}^{2}$. This exsitu demonstration shows the suitability of PSC for nearEarth applications and deep space satellite missions as well. An article published by NASA discusses the possibility of manufacturing PSC in space or in other planets. This will be done thru electrospraying which is similar to inkjet printing and would enable astronauts to build solar cells as they explore. ${ }^{32)}$ These articles show the possibility of using PSC in different space applications, not just in low-earth orbit, but also higher orbits and space explorations.

Kyushu Institute of Technology plans to conduct in-orbit demonstration onboard BIRDS-4, a constellation of three $1 \mathrm{U}(10 \mathrm{~cm} \times 10 \mathrm{~cm} \times 10 \mathrm{~cm})$ CubeSat, that will be deployed from International Space Station (ISS) as early as spring 2021. The satellite flight models were already delivered to JAXA waiting for the launch to ISS in early 2021. To the authors' knowledge, BIRDS-4 is the first demonstration of PSCs in a satellite deployed in low-earth orbit. A nanosatellite, including CubeSat, is a very affordable testbed to do inorbit demonstration of new technology quickly. Using a part of the external panel, new types of solar cells were tested onboard CubeSats or nanosatellites previously. In 2005, XI-V CubeSat from University of Tokyo demonstrated $\mathrm{Cu}(\mathrm{In}, \mathrm{Ga}) \mathrm{Se}_{2}$ (CIGS) solar cells and GaAs solar cells. ${ }^{33)} \mathrm{In}$ 2009, the Japanese Aerospace Exploration Agency (JAXA) launched the Small demonstration satellite (SDS-1) to demonstrate their thin film dual junction (TF2J) InGaP/GaAs solar cell and CIGS. ${ }^{34)}$ In 2012, Horyu-II from Kyushu Institute of Technology first demonstrated dual-junction solar cells. ${ }^{35)}$ These examples demonstrate the significance of nanosatellites in testing novel solar cell technologies in space to gather data on their in-orbit performance.

The purpose of the present paper is to present the research efforts conducted toward the PSCs in-orbit demonstration mission. This paper benefits future research on the prospect of Perovskite solar cells in space thru a long duration mission to observe the performance of PSCs. This paper also helps in identifying the materials that will suit space application of PSC by comparing the most common types of HTM being used.

This paper discusses the difference in performance of PSCs with different HTM selected for the flight test under simulated space environment. The paper also discusses the methodology on how in-orbit data will be gathered, to have an insight on the actual performance of PSCs in space.

From the authors' knowledge, this is the first time that Perovskite solar cells would be sent to space as a payload of a satellite to gather in-orbit data of the PSC's performance in space.

The paper is made of 3 parts. The second part describes the fabrication process of the PSCs, the space environment meth- 
odologies done on the fabricated PSCs as well as the on-orbit demonstration mission which will be the first time Perovskite solar cells are attached to a satellite and deployed in space. Section 3 discusses the results and analysis on the space environment tests done on the PSCs to gain insight on the performance of the PSC with different HTM in space and learn which material is the best for space applications.

\section{Experimental Section}

\subsection{Perovskite solar cell fabrication}

A n-i-p planar Perovskite cell with layer stack of Glass/ Indium Tin Oxide (ITO)/Tin Oxide $\left(\mathrm{SnO}_{2}\right)$ / $\mathrm{FA}_{0.81} \mathrm{MA}_{0.10} \mathrm{Cs}_{0.04} \mathrm{PbI}_{2.55} \mathrm{Br}_{0.40} / \mathrm{HTM} /$ gold $(\mathrm{Au})$ is fabricated. Three different types of hole-transport material were chosen for the PSCs fabricated: Spiro-OMeTAD for organic HTM, CuSCN for inorganic HTM and Carbon (graphite) for Carbonaceous HTM. The perovskite layer is made using $800 \mu \mathrm{L}$ of Dimethylformamide, $200 \mu \mathrm{L}$ of Dimethyl sulfoxide, $0.0182 \mathrm{~g}$ of CsI, $0.2046 \mathrm{~g}$ of FAI, $0.0235 \mathrm{~g}$ of $\mathrm{MABr}$, $0.0771 \mathrm{~g}$ of $\mathrm{PbBr}_{2}$ and $0.6067 \mathrm{~g}$ of $\mathrm{PbI}_{2}$ mixed using a shaker to make the Perovskite solution. The different HTM layers are done as follows: $72.3 \mathrm{mg}$ Spiro-OMeTAD and $1 \mathrm{~mL}$ clorobenzen, $35 \mathrm{mg} \mathrm{CuSCN}$ and $1 \mathrm{~mL}$ Diethyl disulfide, Graphite-Carbon paste.

A $20 \times 20 \mathrm{~mm}$ soda lime glass, doped with $100 \pm 20 \mathrm{~nm}$ of ITO is used as superstrate. The ITO soda lime glass is cleaned using acetone and ethanol and Tin oxide $\left(\mathrm{SnO}_{2}\right)$ is then deposited to the ITO glass. The materials are then put inside a glove box for the spin coating and heating process. The ITO doped glass $/ \mathrm{SnO}_{2}$ is spin coated with $50 \mu \mathrm{L}$ of Perovskite solution and then heated using a hot plate at $150^{\circ} \mathrm{C}$ until the solvents evaporate and Perovskite material crystallizes and turns dark. The HTM solution (except carbon) is then spin coated on the Perovskite cell and heated using hot plate at $100^{\circ} \mathrm{C}$. Gold is finally deposited using vacuum deposition for the Spiro-OMeTAD and CuSCN samples. Each ITO glass contains 3 devices and a total of 24 devices are fabricated for each type of Perovskite HTM. For the final devices attached to the satellites, the glass was then cut to $12 \times 20 \mathrm{~mm}$ and contains two samples. Each satellite carries two samples of each type of HTM.

\subsection{Encapsulation and flight preparation}

To lengthen the lifetime of the PSCs and avoid degradation due to humidity and moisture, the PSCs were encapsulated using a similar method described in Ref. 36). The active area on top of the gold electrode was covered with UV cut film and polyimide/Kapton tape while avoiding any air bubbles from forming. UV light curable glue, Loctite 349, was then applied to attach $1 \mathrm{~mm}$ glass on top of the Kapton tape. The edges are then sealed with RTV-S 691. Finally, metal fasteners were attached on the gold and ITO electrodes to ensure contact between the PSCs electrodes and the satellite electrodes once the cells are attached as shown in Fig. 1(b). The fasteners also avoided the gold plating/graphene layer from being chipped away every time measurements are done with the PSCs. The fabricated PSCs have an active

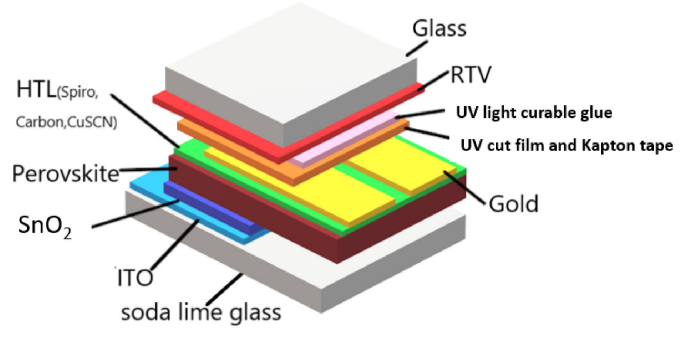

(a)

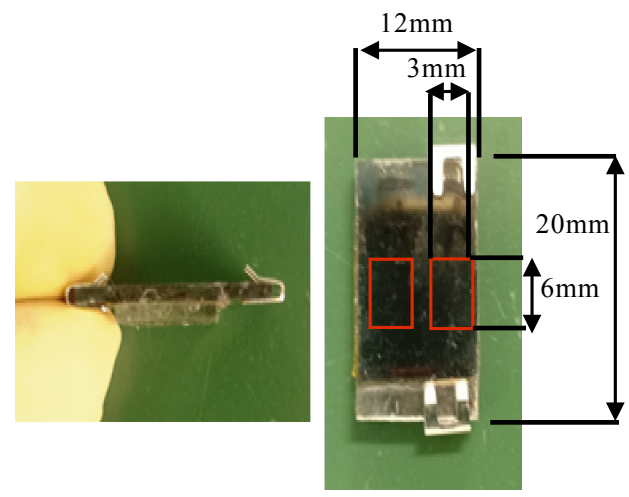

(b)

Fig. 1. (a) Drawing of the PSC layers and (b) final encapsulated PSC with active area shown in red box.

area of $0.18 \mathrm{~cm}^{2}$ shown in a red box in Fig. 1(b). Each square is one device.

\subsection{Solar cell characterization}

The fabricated PSCs are characterized using an AM0 solar simulator SML-2K1MV1 Xenon lamp. Photocurrent-voltage curve measurements are made using Keithley 2400 source meter connected to a computer running the Kickstart application. Prior to J-V measurements, the light intensity is calibrated using a pyranometer MS-802 to approximately $1,400 \mathrm{~W} / \mathrm{m}^{2}$. The surface temperature of the device under test is $30^{\circ} \mathrm{C}$ when measurements are made.

Comparison of scan direction to see the hysteresis stability of the samples are done. The effect of scan rate is also determined by comparing the $\mathrm{J}-\mathrm{V}$ curve at scan rates of $765 \mathrm{mV} / \mathrm{s}$, $110 \mathrm{mV} / \mathrm{s}$ and $25 \mathrm{mV} / \mathrm{s}$ which is varied by changing the delay setting of the voltage sweep by $0,0.1$ and 0.5 seconds, respectively. The delay setting is the time the voltage level is maintained by the source meter. A zero second delay actually means that the voltage level is set for $17 \mathrm{~ms}$ while current is being measured. Current is measured midway of the time the voltage is set. The difference factor is used to compare the measurements and is done by comparing the area under the curve of the plots.

The temperature coefficient is also determined by measuring the characteristics of the PSCs while temperature is increased from ambient temperature to $100^{\circ} \mathrm{C}$ using a hot air blower.

\subsection{Moisture test}

After the PSCs are fabricated, they are exposed to as little moisture/humidity by storing them inside vacuum glove box 
to reduce degradation before encapsulation. The IEC61215 dictates an accelerated life test of 1,000 hours of exposure to $85 \% \pm 5 \%$ relative humidity at $85^{\circ} \mathrm{C}$ for terrestrial solar cells. The device under test should retain high PCE (>98\%) in order to pass. The parameters are measured before and after encapsulation to know if encapsulation helped in retaining the performance of the cells fabricated.

\subsection{Space environment testing}

The following simulated space environment test are done to determine if the fabricated PSCs will survive the conditions in low earth orbit:

(1) Vacuum

(2) Thermal cycle

(3) Ultraviolet light (VUV and NUV)

(4) Vibration (during launch)

From the 24 devices fabricated, at least 2 devices were used for each space environment test to see how each condition affects the performance of the PSCs. The vacuum, thermal cycle, UV light and vibration tests were all done in the Center for Nanosatellite testing (CeNT) and Laboratory of Lean Satellite Enterprises and In-Orbit Experiments (LaSEINE) in Kyushu Institute of Technology, Tobata campus.

\subsubsection{Vacuum}

Two PSC devices were characterized before and after exposure under $4 \times 10^{-5} \mathrm{~Pa}$ of vacuum for 200 hours. Another two PSCs were exposed outside the vacuum chamber at a controlled temperature of $23^{\circ} \mathrm{C}$ and relative humidity of 30 $40 \%$ to enable comparison of the perovskite cells fabricated against atmospheric environment. Samples are weighed before and after vacuum test using AMPUT APTP-453 digital scale with an accuracy of $0.01 \mathrm{~g}$ to see if outgassing occurred.

\subsubsection{Thermal cycle}

To ensure that air and moisture has minimal to no effect on the degradation of the cells during thermal cycling, the PSCs were put inside a pouch made of aluminium sheet with air and moisture vacated. Air and moisture were vacated by filling the pouch with nitrogen gas then purging the air inside. This is done for 3 times to ensure the inside of the pouch is $\mathrm{N}_{2}$ gas only. The aluminium pouch is then put inside a Despatch 900 thermal cycle chamber. The cells were then cycled from -40 to $85^{\circ} \mathrm{C}$ for 250 cycles and performance were measured every 50 cycles. ${ }^{37)}$ Each cycle takes 25 minutes and no soaking was done for each cycle.

\subsubsection{UV light}

Ultraviolet light has been shown to degrade Perovskite solar cells due to the photocatalytic effect in $\mathrm{TiO}_{2}$ which leads to creation of trap sites and recombination of electrons and holes and reduced output of the device. ${ }^{14)}$ This led to the use of other ETL such as $\mathrm{Al}_{2} \mathrm{O}_{3}$ and $\mathrm{SnO}_{2}{ }^{38)}$ The fabricated PSCs use $\mathrm{SnO}_{2}$ and a UV cut film with measured transmittance as shown in Fig. 2, to ensure that UV will not degrade the PSCs.

To test how UV environment space affects the fabricated PSC, the cells were exposed to Near UV (NUV) using a Hamamatsu L2273 Xenon (Xe) lamp and Vacuum UV (VUV) using a Hamamatsu L12542 Deuterium (D2) lamp.

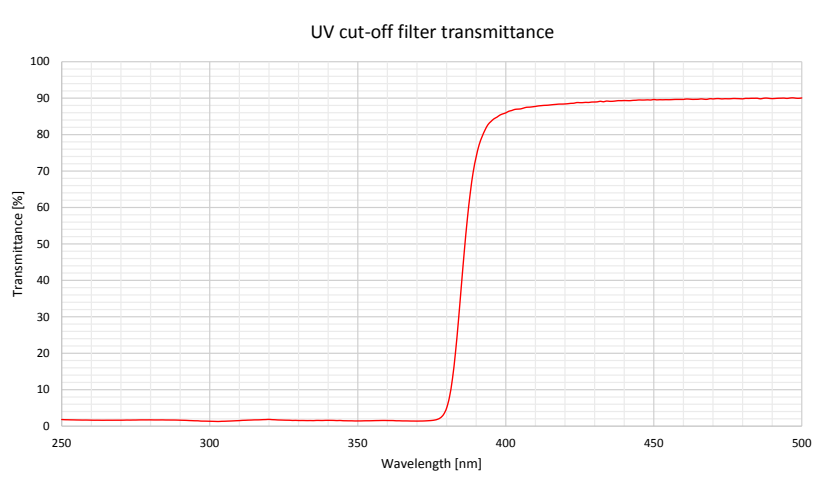

Fig. 2. Attached UV cut film transmittance percentage.

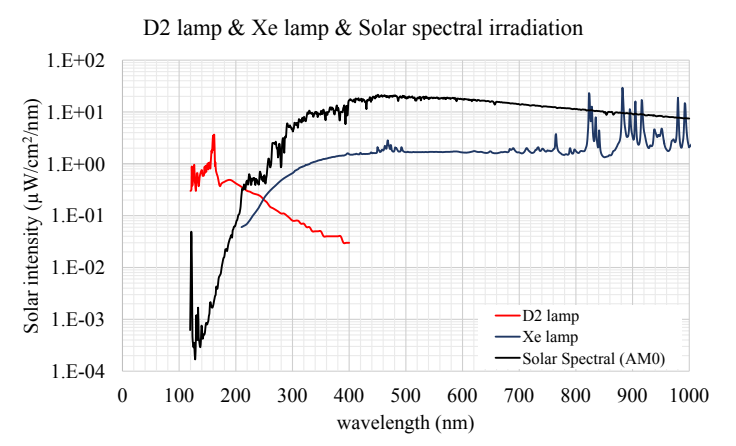

Fig. 3. Spectral response of Deuterium (D2) and Xenon lamp vis-à-vis AM0 Solar spectrum.

For each type of UV radiation, a different batch of PSCs were used. The UV spectral radiation in space versus the UV lamps used are plotted in Fig. 3. Both the NUV and the VUV test exposed two PSC devices for each type of HTM to UV radiation. Two PSC devices were also kept inside the chamber but not exposed to UV radiation. This is to identify if UV directly affected the performance of the cells or the temperature and vacuum environment does.

For the NUV test, the cells were exposed to a light intensity of $23 \mathrm{~mW} / \mathrm{cm}^{2}$ at a vacuum condition of $3.5 \times 10^{-3} \mathrm{~Pa}$. This raised the temperature for the cells to $80^{\circ} \mathrm{C}$ for the entire duration of the test. For reference, sun intensity in space for $200-400 \mathrm{~nm}$ is $10.85 \mathrm{~mW} / \mathrm{cm}^{2}$. The PSCs were exposed to 450 equivalent sun hours which is the same as one month of exposure in ISS orbit. For the VUV test, the PSCs are exposed to an average solar intensity of $106 \mu \mathrm{W} / \mathrm{cm}^{2}$ at a temperature of $-40^{\circ} \mathrm{C}$ and vacuum condition of $1.6 \times 10^{-4} \mathrm{~Pa}$. For reference, solar intensity in space at $120-200 \mathrm{~nm}$ is $10.44 \mu \mathrm{W} / \mathrm{cm}^{2}$. The VUV test was repeated twice for the same samples. During the first test, the UV cut film was attached which were removed during the second test, to identify if the UV cut film has a significant effect on the performance of the PSCs.

\subsubsection{Vibration launch environment}

To ensure the survivability of the PSC and that they would remain attached to the satellites during launch, the PSC attached to the satellites went thru acceptance test level (AT level) vibration test for the launch to ISS. Shown in Fig. 4(a) is the vibration machine and the placement of the satellites inside the pod for the vibration test. Figure 4(b) is the Power 


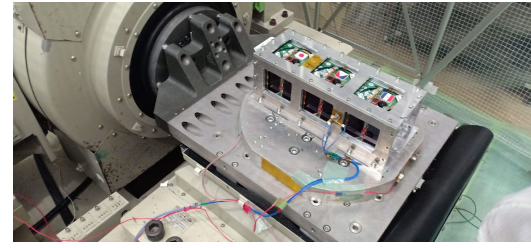

(a)

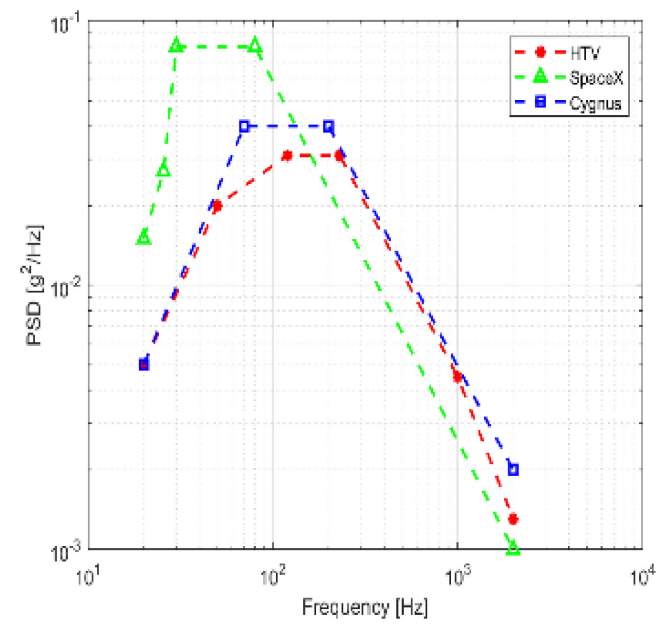

(b)

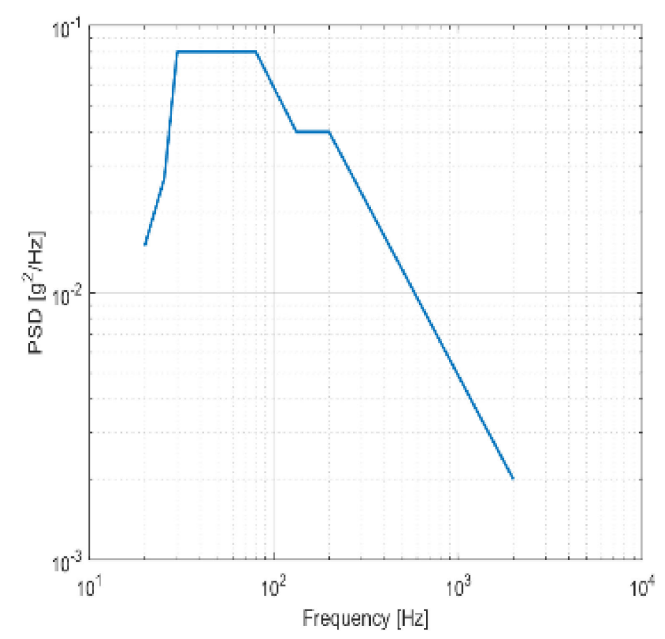

(c)

Fig. 4. (a) Vibration test machine and satellites inside pod for vibration test, (b) random vibration PSD of HTV, SpaceX and Cygnus rockets, (c) envelope of the PSD profiles of the three launchers.

spectral density (PSD) used for the testing. The root mean square value of the acceleration is $6.79 \mathrm{Grms}$. The test condition was derived by taking the envelope of the random vibration profile of HTV, SpaceX and Orbital Cygnus, the possible launchers to ISS.

\subsection{First perovskite solar cell onboard satellite:} BIRDS-4 PSC mission

The fourth iteration of the Joint Global Multi-Nation Birds Project or BIRDS-4 project, is a constellation of satellites consisting of three identical satellites built by students from Japan, Philippines and Paraguay. Each satellite is attached with 2 PSC devices. The Philippine satellite carries PSC with Spiro-OMeTAD HTM, Paraguay satellite carries PSC with
Carbon HTM and Japan satellite carries PSC with CuSCN HTM. Inside each satellite is a Perovskite Solar Cell Measuring Unit or PSCMU which collects the solar cell current, voltage, surface temperature and irradiance level as shown in Fig. 5. The electrical circuit of the PSCMU is shown in Fig. 6 which does a voltage sweep from $1.4 \mathrm{~V}$ to $0 \mathrm{~V}$ with a total of 110 current-voltage points collected for the J-V curve. The whole measurement cycle takes around 3 seconds to finish and 12 seconds to save in the flash memory. The frequency of data collection is variable and set via command from the ground station. The ground station command dictates the length of time (in minutes) before the next sampling is done.

These data are processed by the PIC microcontroller and stored in a flash memory for future download by a ground station for further analysis. From the 4-byte float format of the measured data, the voltage, current, temperature and solar intensity data are converted to 2-byte integer format. This is done by multiplying the float value by 10,000 for the voltage and by 100 for the current, temperature and solar intensity. The 2-byte integer part is then stored to the flash memory to reduce saving time and amount of data needed to be downloaded to complete one set of data. A total of 440 bytes is needed to be downloaded in order to reconstruct an I-V curve and analyze the characteristics of a single PSC device. Since there are two PSC devices in each satellite, 880 bytes of I-V data is stored each measurement, which is equivalent to 11 packets of data downlink. Figure 7 shows the panel where the PSC are attached together with the TMP36FSZ temperature sensor and SFH2430 photodiode as light intensity sensor.

\section{Results and Discussion}

\subsection{Photovoltaic performance}

Shown in Fig. 8 is a measurement of the champion samples for each type of fabricated PSC. Table 3 shows the parameters of the champion PSC of with each type of HTM. Organic HTM achieved the highest PCE while carbon HTM showed low fill factor compared to the other samples. Figure 9 shows the boxplots for the distribution of parameters of the fabricated devices. The boxplot shows the distribution of data in quartiles using thick bands and thin lines. Each quartile represents the range of value for $25 \%$ of the data. In the boxplot, the first quartile is from the thin line to thick band. The second quartile is from the thick band to the middle line. The third quartile is from the middle line to the end of the thick band, and the fourth quartile is from the end of the thick band to the end of the thin line. The middle line indicates the median while the ' $\mathrm{X}$ ' shows the mean of the data set. ${ }^{39)} \mathrm{A}$ shorter thick band means that the data are concentrated in a certain value and indicates consistency of the samples fabricated. The reverse can be said if the longer, which means there's variability in the values of the fabricated samples. From the figure, it can be seen that for Voc, Spiro samples have very consistent value and for PCE, Carbon has very consistent value. This shows that Carbon PSC fab- 


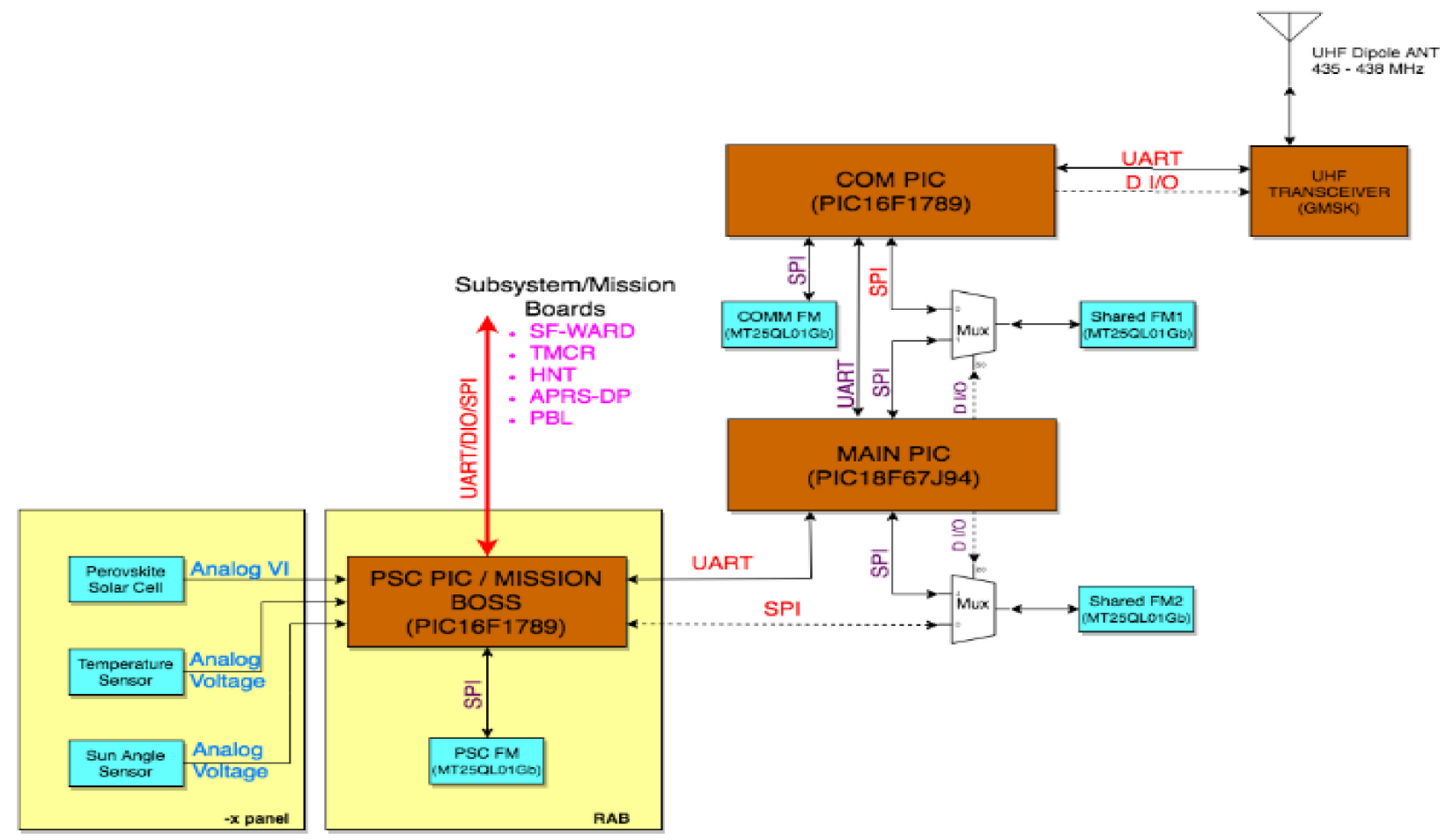

Fig. 5. Block diagram of perovskite solar cell measurement unit.
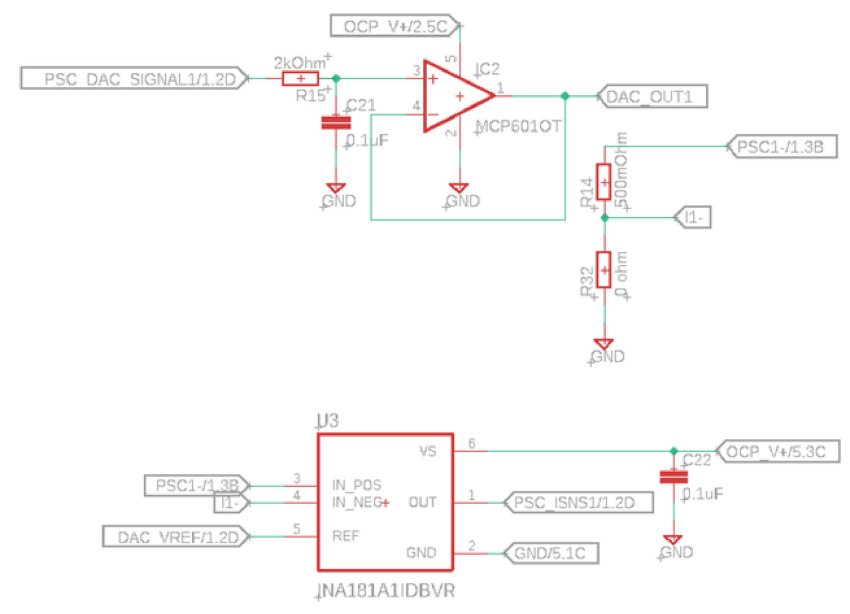

Fig. 6. Circuit diagram of the Perovskite solar cell measurement unit.

rication produces cells with more consistency than Spiro and CuSCN samples.

From the 24 devices fabricated, the average PCE are 12.67, 4.76 and 7.75 for Spiro-OMeTAD, CuSCN and Carbon devices, respectively. Samples with PCE less than three standard deviation (3o) from the mean sample were considered bad samples, since three standard deviations should contain $99.7 \%$ of data. The $3 \sigma$ for Spiro is 3.02, -4.09 for $\mathrm{CuSCN}$ and 2.77 for Carbon samples. Under this requirement, 22 samples for Spiro-OMeTAD, 22 samples for CuSCN and 18 samples for Carbon were included.

\subsection{Scan direction and scan rate}

Results on the effect of hysteresis based on scan direction is shown in Fig. 10. It shows that J-V curve of the samples in forward scanning and reverse scan. The amount of hysteresis, determined thru the difference in area of the J-V curve shows that carbon PSC has the most hysteresis with a difference factor of $3.87 \%$, followed by Spiro-OMeTAD and CuSCN with PCE difference of $0.93 \%$ and $0.69 \%$, respectively. From this result, it can be said that the direction of scanning won't have a huge effect on the measured parameters. Backwards scan direction will be used in measuring the PSCs as literature mentions that backwards measurement is less affected by scan rate and has more stable reading at the lower voltage range of the measurement. ${ }^{40)}$

Shown in Fig. 11 are the results of the effect of scan rate. Spiro-OMeTAD and Carbon have a difference factor of $2.08 \%$ and $2.13 \%$, respectively, and $\mathrm{CuSCN}$ with $33.5 \%$. The scan rate has no significant effect for Spiro-OMeTAD and Carbon but for CuSCN, there is a significant change in measurement as the scan rate changes. This is important as it is preferred to have a fast measurement time since the satellite is tumbling/spinning and solar intensity might change quickly. From this result, $765 \mathrm{mV} / \mathrm{s}$ scan rate is used in the measurement of the PSCs.

\subsection{Temperature coefficient}

Figure 12 shows the PCE as the temperature is increased and from here, the temperature coefficient can be derived as $-0.14 \% /{ }^{\circ} \mathrm{C}$ for Spiro-OMeTAD, $-0.01 \% /{ }^{\circ} \mathrm{C}$ for $\mathrm{CuSCN}$ and $-0.04 \% /{ }^{\circ} \mathrm{C}$ for Carbon HTM. For reference, terrestrial monocrystalline solar cells have temperature coefficient of $-0.5 \% /{ }^{\circ} \mathrm{C},{ }^{41)}$ and triple junction solar cells have temperature coefficient of $-0.09 \% /{ }^{\circ} \mathrm{C} .{ }^{42)}$ The best temperature coefficient is CuSCN but the PCE is very low which makes the data insignificant, hence Carbon HTM display best temperature stability among the samples fabricated. 

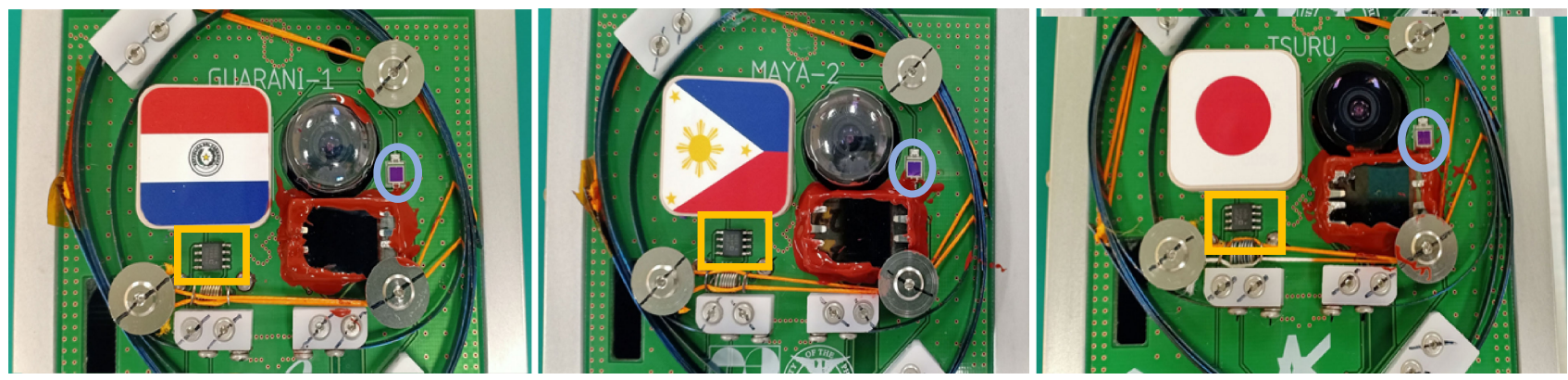

Fig. 7. PSC samples attached to each satellite of BIRDS-4 with photodiode (circled) and temperature sensors (squared).

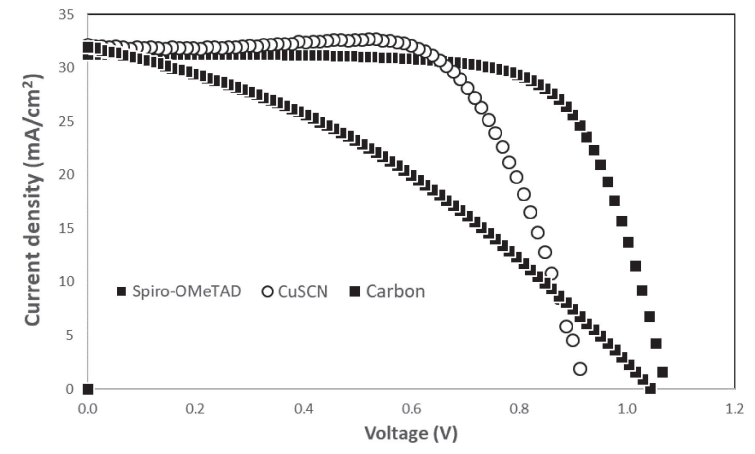

Fig. 8. Current density-voltage curves of the champion PSC of the three types of HTM.

Table 3. Photovoltaic parameters of the Champion PSC for the three types of HTM.

\begin{tabular}{ccccc}
\hline HTM type & $\begin{array}{c}\text { Voc } \\
(\mathrm{V})\end{array}$ & $\begin{array}{c}\text { Jsc } \\
\left(\mathrm{mA} / \mathrm{cm}^{2}\right)\end{array}$ & FF & $\begin{array}{c}\text { PCE } \\
(\%)\end{array}$ \\
\hline Spiro-OMeTAD & 1.07 & 33.54 & 0.68 & 24.28 \\
CuSCN & 0.93 & 32.70 & 0.66 & 20.08 \\
Carbon & 1.06 & 31.98 & 0.36 & 11.99 \\
\hline
\end{tabular}

\subsection{Moisture}

Figure 13 shows a PSC with CuSCN HTM before and after encapsulation showing that the encapsulation process had a significant effect on the PCE of the PSCs with a difference factor of $10 \%$. The reduction in PCE is most probably caused when the pristine samples were taken out of the glove box for initial performance measurement and encapsulation which exposed them to the atmospheric environment which started the degradation of the material. Humidity and oxygen in the environment must have begun reacting with the perovskite material so when the samples were measured again after encapsulation, the performance has reduced already.

Figure 14(a) shows an image of the cells before the moisture test while Fig. 14(b) and 14(c) shows the cells without encapsulation and with encapsulation after the moisture test, respectively. It is clear from the change in the active material that moisture extensively affected the PSC, especially those which are not encapsulated. Figure 14(d) shows the degradation trend of the PCE of the cells that are non-encapsulated and Fig. 14(e) shows the degradation trend for cells which are encapsulated. Although the test shows that the encapsulation method wasn't able to completely prevent the degrada-

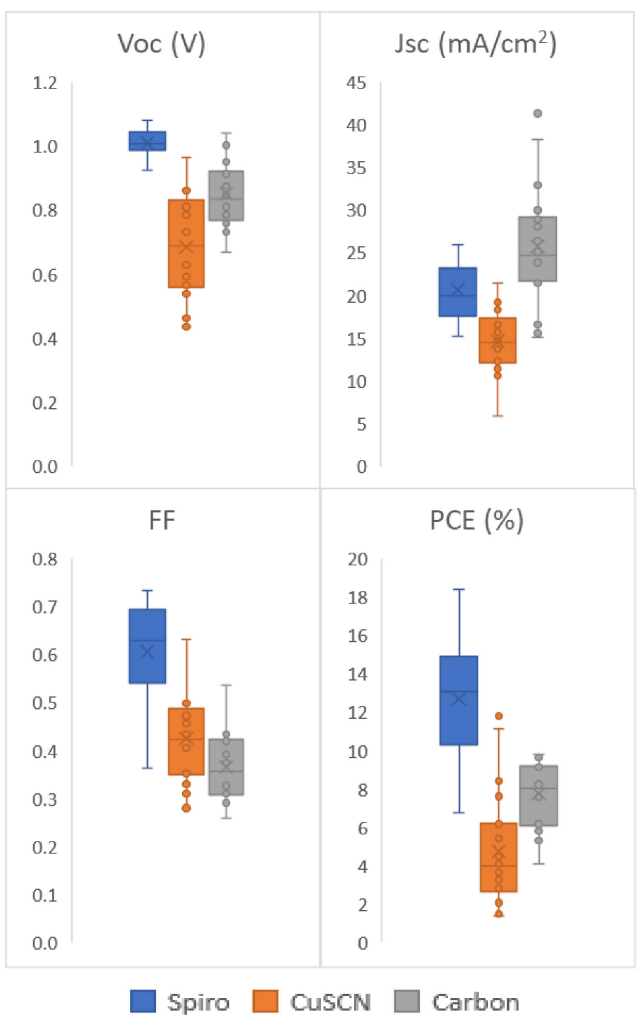

Fig. 9. Parameter distribution of fabricated PSCs.

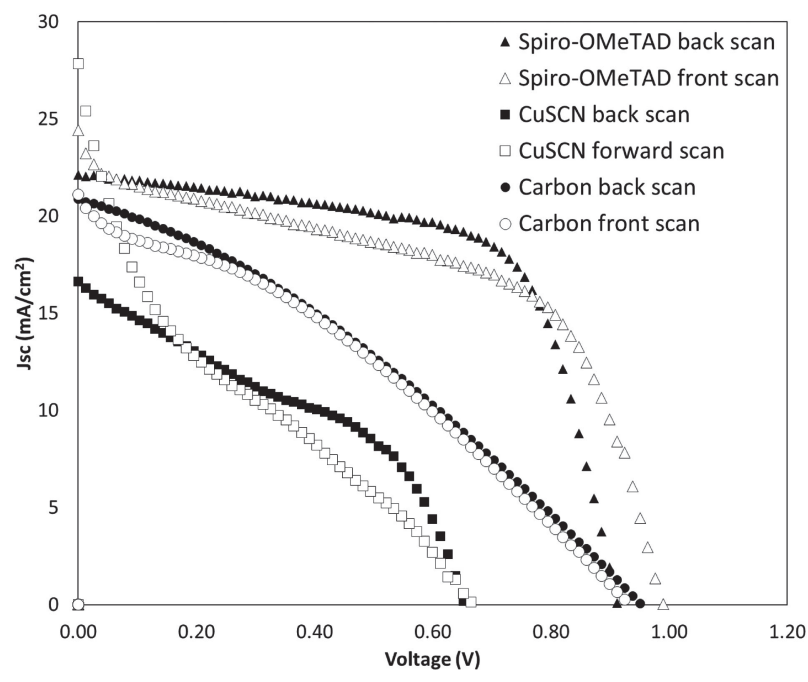

Fig. 10. Comparison of PSC samples based on scan direction. 


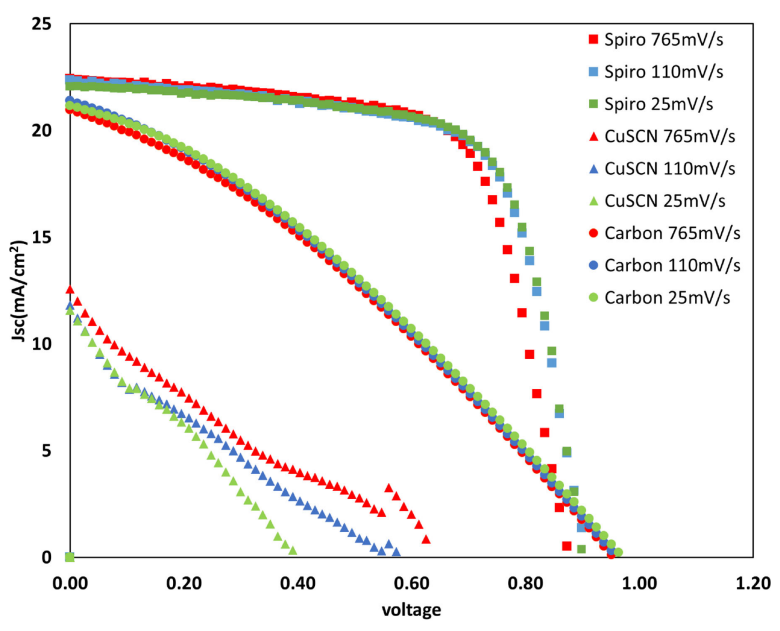

Fig. 11. Comparison of PSC samples based on scan rate.

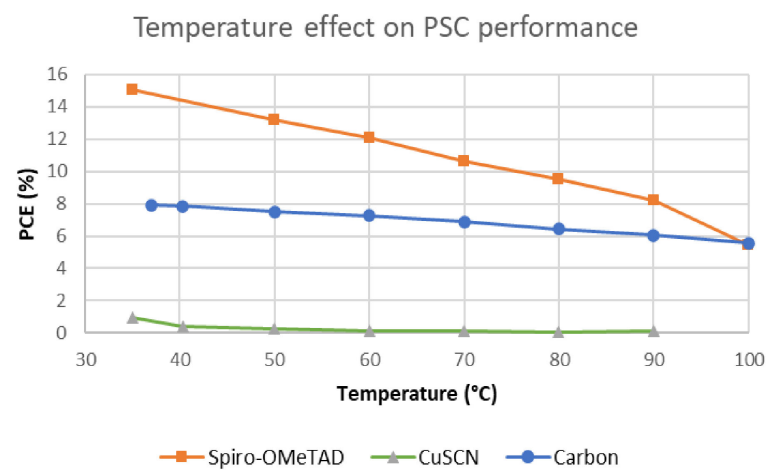

Fig. 12. Change in PCE of cells with temperature.

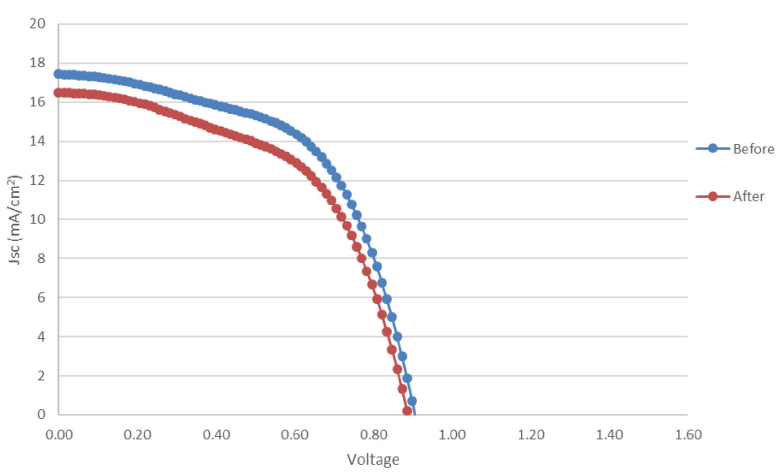

Fig. 13. Device efficiency before and after encapsulation.

tion of the cell, it shows that encapsulation can still slow down the degradation of the PSC indicated by the longer time the PCE is reduced. If we scale the IEC61215 standard which is done to ensure reliability of the encapsulation for 20 years by exposing the solar module to $85 \%$ relative humidity at $85^{\circ} \mathrm{C}$ for 1,000 hours and retain $80 \%$ of its original efficiency, we can say that Carbon PSC which retained its PCE above $80 \%$ for 8 days should be able to retain its performance under normal environmental humidity and temperature for 3.84 years. For CuSCN, it retained its performance of above $80 \%$ for less than 1 day which is equivalent to approximately

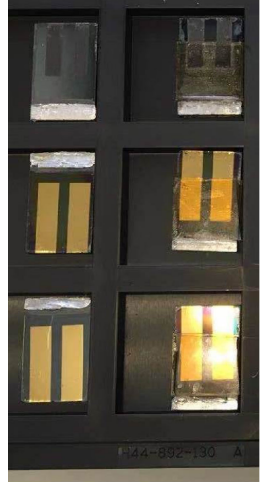

(a) (b)

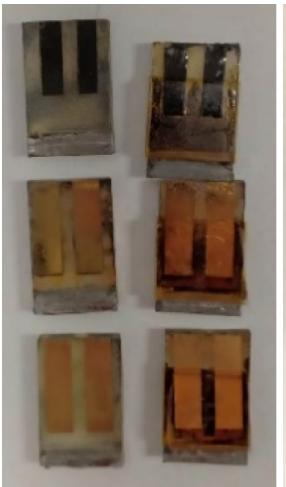

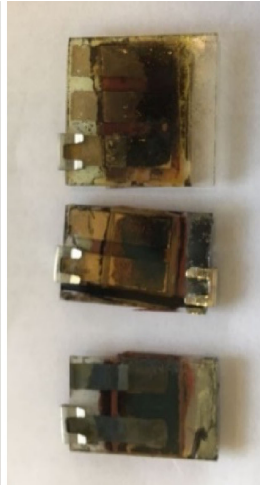

(c)

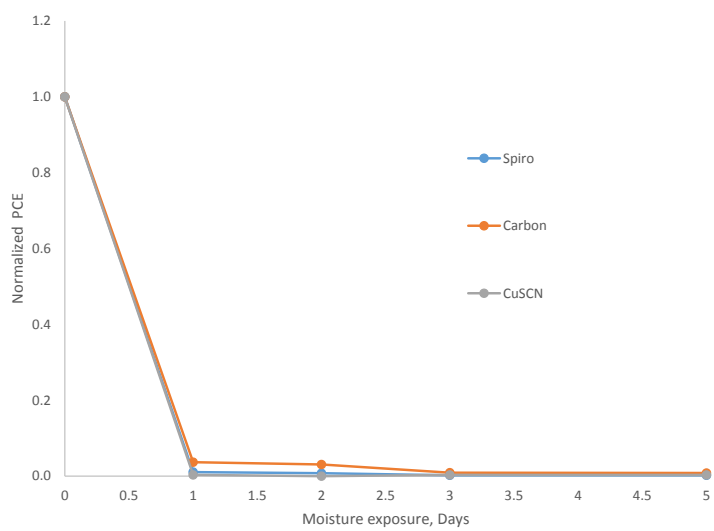

(d)

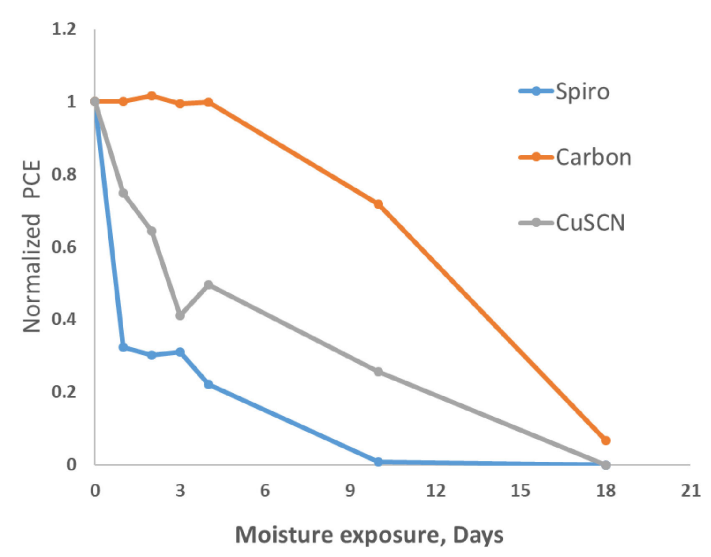

(e)

Fig. 14. PSC samples (a) before moisture test, (b) non-encapsulated cells after moisture test, (c) encapsulated cells after moisture test. Change in PCE overtime of (d) non-encapsulated PSCs and (e) encapsulated PSCs under high humidity environment.

6 months and Spiro which quickly degraded to less than $80 \%$ for about 9 hours would have an equivalent of 2 months. This shows that the PSCs have a chance to still work after waiting for several months in earth prior to the satellites' launch into space.

\subsection{Vacuum environment}

The effect of vacuum and normal atmosphere before and after 200 hours is plotted in Fig. 15. The graph shows that exposure to vacuum still affects the performance of the cells as also observed in Ref. 43). It shows that there is $25 \%$ and $35 \%$ change in PCE observed for the Spiro-OMeTAD de- 

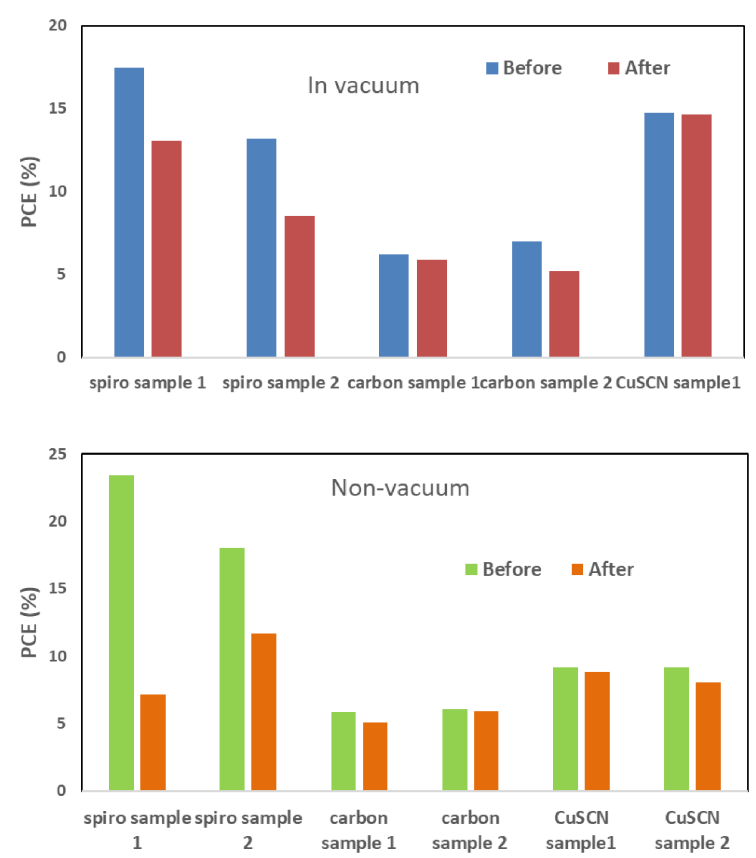

Fig. 15. Comparison of PCE to fabricated PSCs exposed under vacuum and under normal pressure environment.

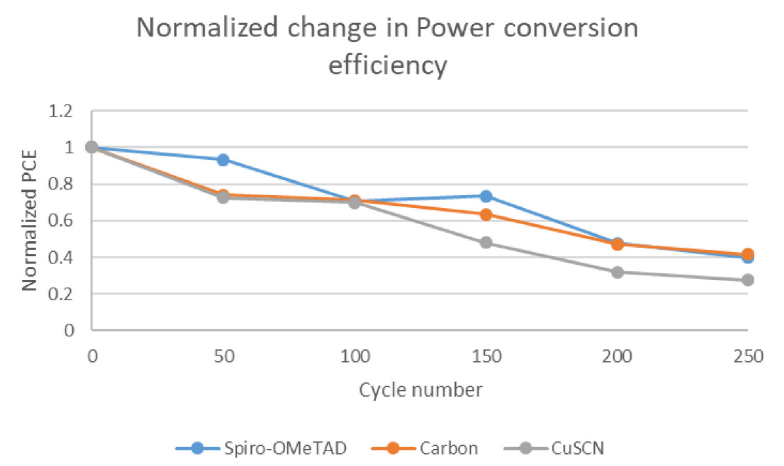

Fig. 16. Normalized PCE comparison of three types of PSC after thermal cycling test.

vices while a smaller $0.4 \%$ change was observed in $\mathrm{CuSCN}$. In general, it shows that the fabricated cells with their encapsulant degraded less in vacuum. The change in weight of some samples before and after the vacuum is less than 0.01 gram change while the rest of the samples did not change their weight. Therefore, there are no significant change in the weight. The optical characteristics were also compared by visual inspection for any cracks, chips and discoloration before and after the vacuum test. No significant change also occurred upon visual analysis of the samples. Carbon and inorganic HTM CuSCN showed to degrade less in vacuum compared organic HTM Spiro-OMeTAD.

\subsection{Thermal cycle environment}

Figure 16 shows the effect of thermal cycle in each sample which shows how the number of cycles degraded the efficiency of the PSC to less than half of the original power conversion efficiency. Among the parameters measured, Voc shows the highest rate of change indicating that the changing temperature has damaged the interface between the layers of

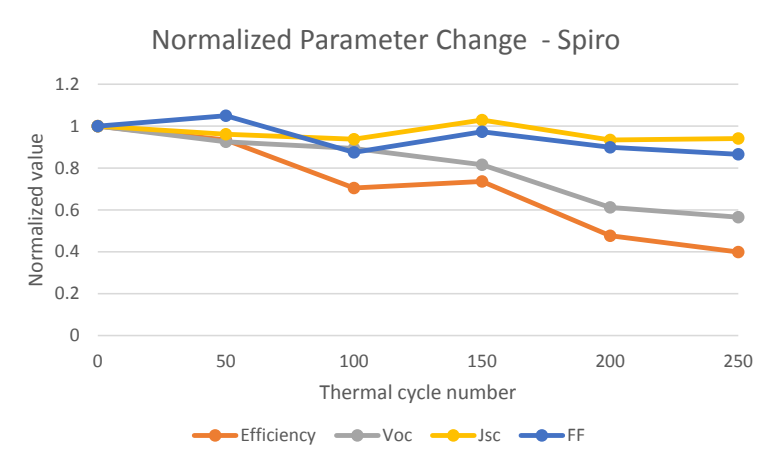

Normalized Parameter Change - CuSCn

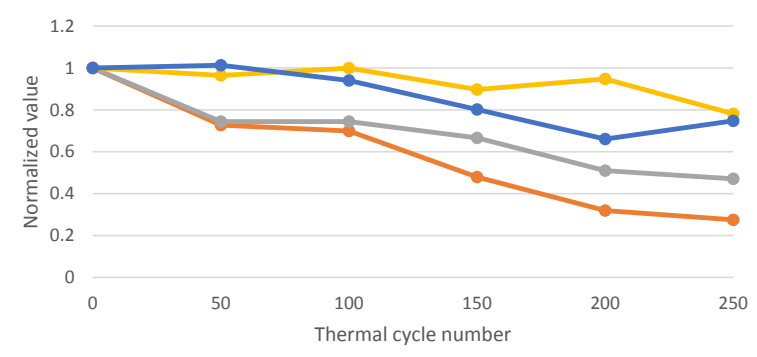

$\leftrightarrow$ Efficiency $\rightarrow$ Voc $\multimap$ Jsc $\multimap F F$

Normalized Parameter Change - Carbon

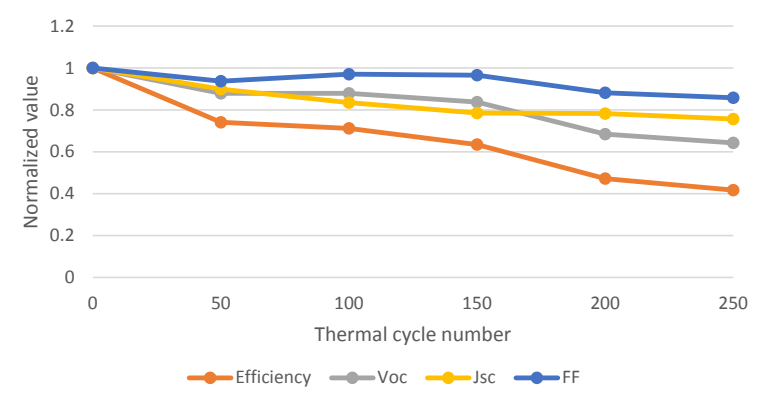

Fig. 17. Comparison of the normalized parameters of the three types of PSC after thermal cycling test.

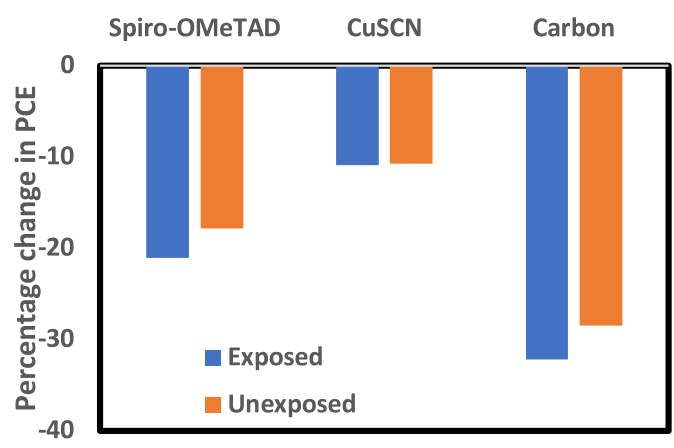

Fig. 18. Comparison between the change in PCE between the PSCs exposed and not exposed to VUV radiation.

the PSC which in turn decreases the overall PCE of the PSC as shown in Fig. 17.

\subsection{Ultraviolet light radiation}

The first VUV test result shown in Fig. 18 show that both the exposed and unexposed cells degraded during the test, with carbon cells degrading the most among the three types of PSC. Comparing the percent change in the PCE of the exposed and unexposed cells to VUV radiation shows that they 


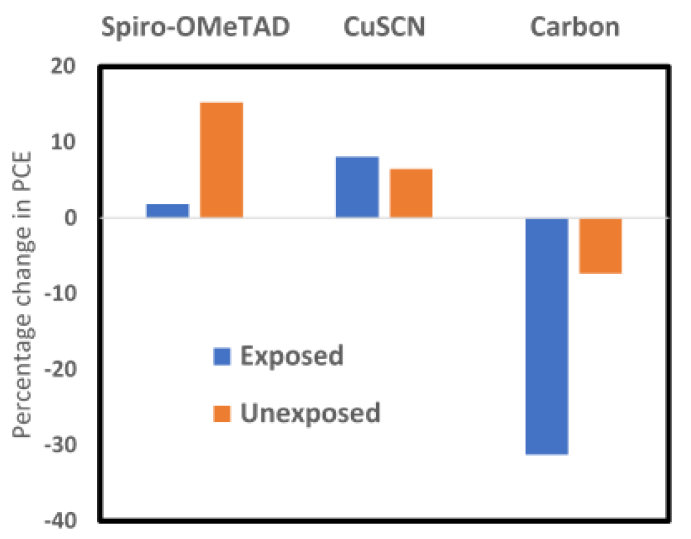

Fig. 19. Comparison between the change in PCE between the PSCs exposed and not exposed to VUV radiation without the UV cut filter.

Change in PCE during NUV exposure

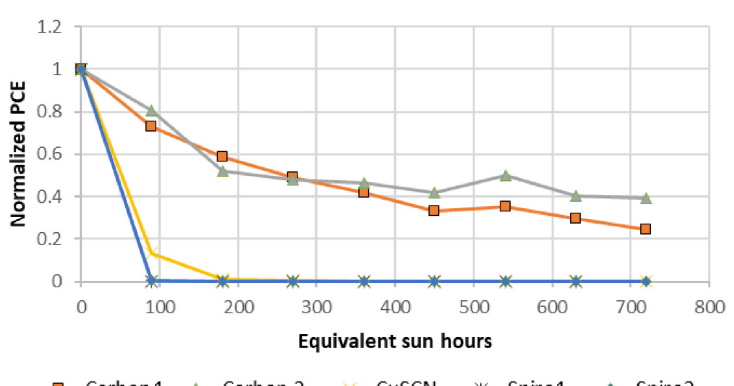

Fig. 20. Change in PCE of PSC samples exposed to NUV radiation for a 1-month equivalent exposure in space.

degraded at the same rate. This indicates that VUV radiation did not affect the cells and it is the temperature and vacuum environment which induced the degradation of the cells.

The result of the second VUV test shown in Fig. 19 shows that the exposed cells did not degrade unlike the cells exposed during the first VUV test with UV cut film attached. A study made by Ref. 44) pointed to UV treatment as a cause for modification of the bulk properties of PSCs and energy equilibrium at the interfaces. This is done by passivation surface and grain boundary defects. The removal of the UV film allowed the UV light to treat the defects on the cells caused by temperature and vacuum which resulted to better performance compared when the PSCs has UV cut film.

The characteristics of the PSCs were measured daily throughout the 9 day NUV test. The change in PCE is plotted in Fig. 20. It is noticeable how CuSCN and Spiro quickly degraded unlike Carbon which slowly degraded over time. Results show that after the test, the PSCs exposed to NUV degraded significantly compared with the devices not exposed to NUV. Spiro-OMeTAD and CuSCN devices completely stopped working after the test. This shows that the long-term exposure to increased temperature plays a significant role in the degradation of the cells. This also shows that carbon HTM is able to still function after long term exposure to high temperature, unlike the PSCs with organic and inorganic HTM.

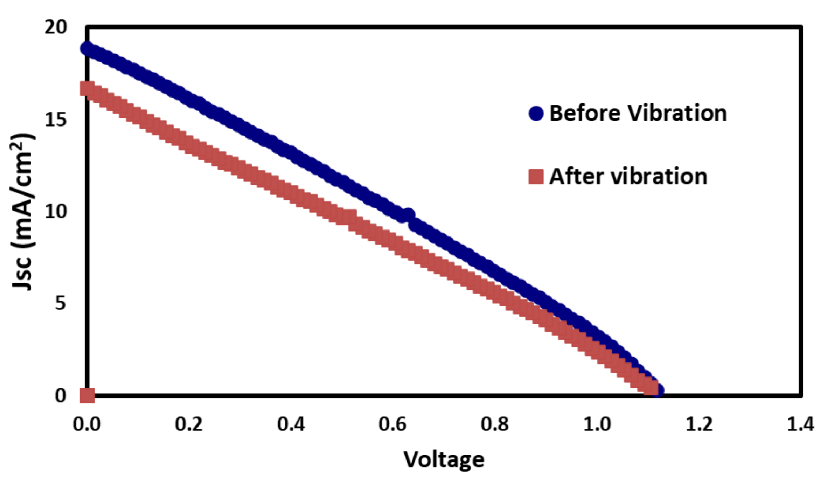

Fig. 21. Comparison of J-V performance of PSC before and after vibration test.

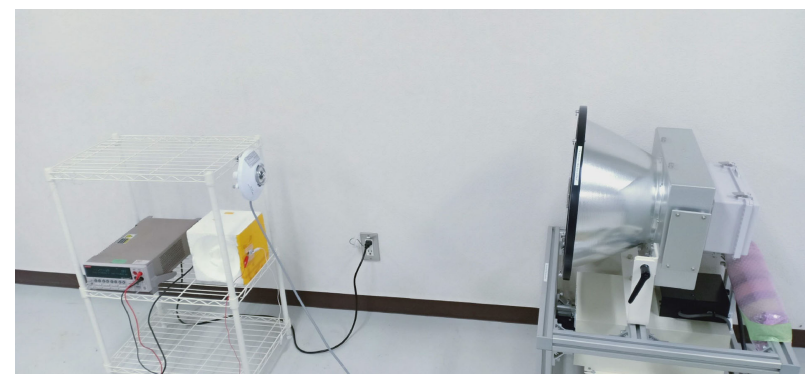

Fig. 22. Test setup using sun simulator, sourcemeter and pyranometer as irradiance reference.

\subsection{Vibration environment}

The vibration test results showed that the PSCs and PSC attachment method withstood the acceptance test vibration levels from the envelope of the vibration profiles of common ISS launch vehicles. No cracks or chipped particles from the PSC samples were observed after the vibration test. Shown in Fig. 21 is a comparison between a carbon PSC before and after vibration test. The discrepancy of the results is from human errors and inaccuracies during measurement. Test results show that the change in measured current is either due to a slight increase in distance of approximately $2-3 \mathrm{~cm}$ from the light source and the solar cell or a 10-15 degree change in angle of the solar cell while being illuminated or a combination of both. The change in distance and angle is a result of the cell being placed vertically from a platform which is moved from its location based on the measured irradiance of the pyranometer being used as reference as shown in Fig. 22. Care was taken to maintain consistent placement of cells but minute changes in distance and angle of the cell could still happen as a result of human error.

\subsection{Perovskite solar cell mission}

To ensure accuracy of data downloaded, calibration is done to the PSC measurement unit by comparing its measurement to a source meter. Shown in Fig. 23 is a result after calibrating the PSCMU. It shows the measurement is almost identical with the sourcemeter with the difference being the lower resolution of the analog-to-digital converter for the PSCMU and current sensor limitation. A slight change in Voc was observed as a result of the increase in 


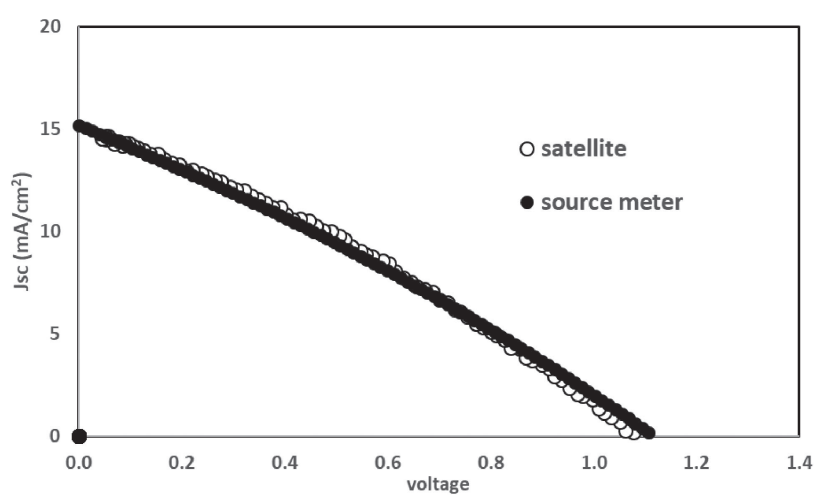

Fig. 23. Comparison between source meter and satellite PSC measurement unit.

temperature between the measurements done using the sourcemeter and the satellite. The change in Voc ranges from $0.0027-0.0091 \mathrm{~V} /{ }^{\circ} \mathrm{C}$.

The BIRDS-4 mission to measure the PSC is also tested in the flight model of the satellites by running the mission and downloading the data. Figure 24 shows the characteristics of the cells attached and the processed downloaded data from the satellites after one month of attachment. It can be observed how the data downloaded significantly degraded only 1 month after attachment with Spiro-OMeTAD samples degrading the worst. This result is consistent with the result of the moisture test in section 3.4 where Fig. 14(e) shows Spiro to be the PSC type to degrade the fastest. The amount of change in parameters wasn't as expected from the moisture test since we expect a less drastic change after encapsulating the cell. This test result shows how more advanced encapsulating methods are needed for future satellite missions using PSC to ensure they are still working when sent to space.

Once the BIRDS-4 satellites are deployed in space, they will wait for a command from the ground station to execute the PSC mission. When a command is received and processed by the onboard computer of the satellite, it will activate the PSCMU and start measuring the current and voltage readings from the PSCs. The saved data is stored in a flash memory awaiting another command to downlink these data to the ground station.

In the event that uplink communication between the ground station and the satellite is not achieved, the satellite is programmed to automatically execute the PSC mission for three consecutive days. The data collected is also automatically downlinked by the satellite and this process repeats every 36 days. The other days are allotted for other missions of the satellite.

Finally, the collected data will be analyzed to see the performance of the PSC in low-earth orbit.

\section{Conclusion}

The attractiveness of PSC with its high power density, low manufacturing cost and high power conversion efficiency compared to triple junction solar cells, has placed it as a potential material as power source for space applications. In
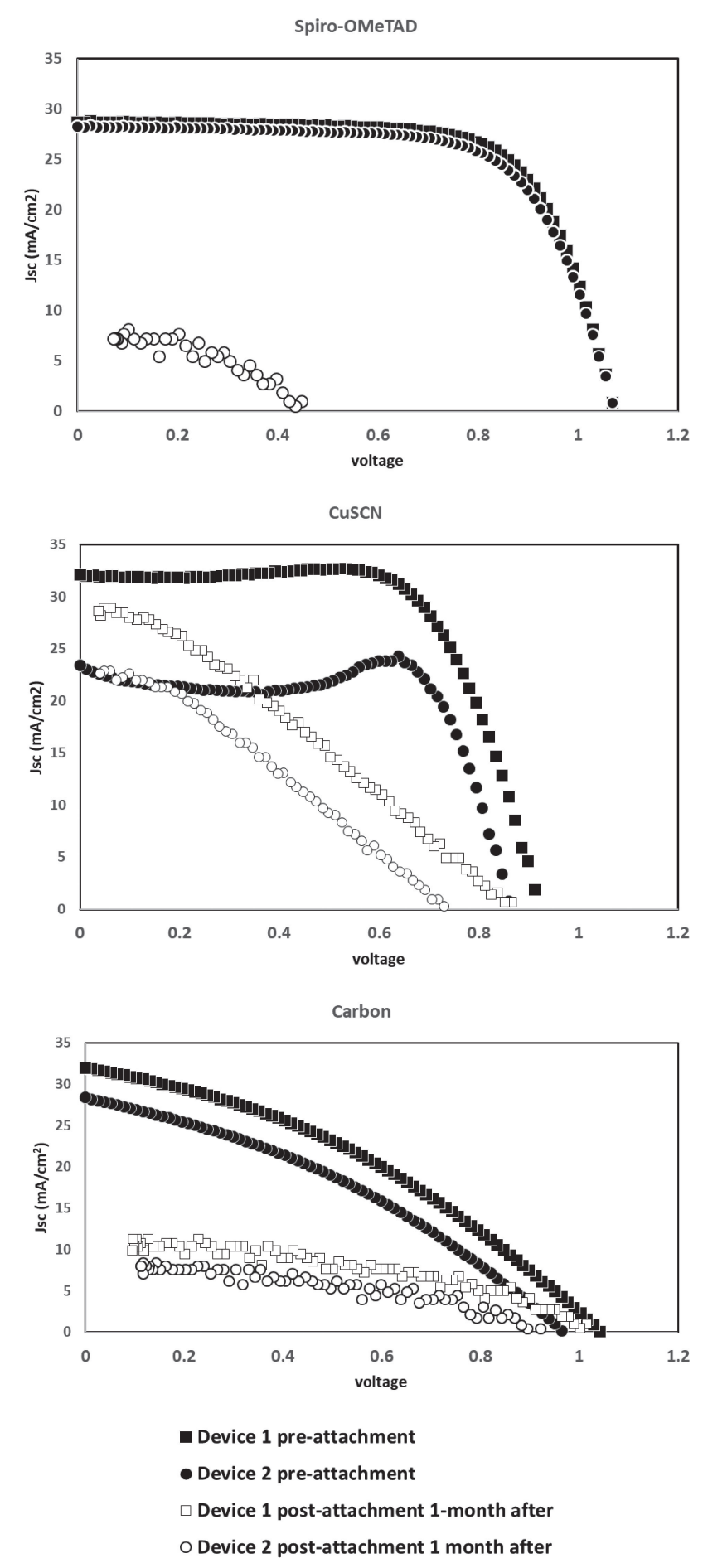

Fig. 24. Comparison between devices attached to the BIRDS-4 satellite before attachment and 1 month after attachment.

line with this, the BIRDS-4 project, slated to be deployed in space from ISS in 2nd quarter of 2021 with a mission to send the first PSC onboard a satellite to evaluate their performance in actual space environment. Design on how to attach encapsulated PSCs and measure their performance in a satellite has been done. Extensive test under different simulated space environment conditions such as temperature cycling, vacuum and UV light has shown how PSCs with different HTMs (organic, inorganic and Carbonaceous) would perform under space conditions. 
Perovskite SCs with Spiro-OMeTAD showed high PCE that is competitive with existing solar cell technologies but its lifetime is poor under the environments tested. Inorganic HTM CuSCN also performed poorly while Carbon HTM showed the best performance in terms of lifespan and stability under the tested space environment. This is mainly because of their hydrophobic property and thermal stability. The downside to Carbon is their low PCE compared to existing solar cell technologies because of their lower hole mobility compared to other HTMs. This conclusion corroborates with researches reviewed in Ref. 45).

For low earth orbit applications, where temperature conditions do not vary extremely and where sunlight time is limited, high efficiency PSCs such as those using organic and inorganic HTM are recommended with research focusing on better encapsulation and processing to allow for longer lifetime of the cells. For Geostationary missions, with environments reaching extreme values and continuous exposure to the sun, the PSCs with Carbon HTM are recommended as it shows greater survivability over long period of time. With the significant weight reduction of PSCs, larger solar paddles can be mounted on satellites to compensate for the reduced PCE so as to meet the energy requirements of the satellite. It is therefore concluded to focus research on improving the PCE of Carbon HTM PSCs as they show the most promise for space applications.

Future work would entail larger modules of Perovskite solar cells tested in space with advanced encapsulation to further prevent the effect of humidity and moisture to the PSC.

The results of the initial operation and data gathered from the PSC mission of BIRDS-4 will be published once the satellite has begun its operation in space.

\section{Acknowledgments}

This research is supported, in part, by JSPS Core-to-core program, B. Asia-Africa Science Platforms, Sustained Support for Local Space Technology and Applications Mastery, Innovation and Advancement (STAMINA4Space) Program and Space Science and Technology Proliferation through University Partnerships (STEPUP) Project.

\section{References}

1) Smil, V.: Photovoltaics in Satellites, https://spectrum.ieee.org/ aerospace/satellites/photovoltaics-in-satellites (accessed 11 November 2020).

2) Fraas, L. M. and Partain, L. D.: Solar Cells and Their Applications, 2nd ed., Wiley, Hoboken, N.J., 2010.

3) Torchynska, T. and Polupan, G.: High Efficiency Solar Cells for Space Applications, Superficies y Vacio, 17 (2004), pp. 21-25.

4) Kojima, A., Teshima, K., Shirai, Y., and Miyasaka, T.: Organometal Halide Perovskites as Visible-Light Sensitizers for Photovoltaic Cells, J. Am. Chem. Soc., 131, 17 (2009), pp. 6050-6051.

5) Oxford PV: Oxford PV Sets World Record for Perovskite Solar Cell, https://www.oxfordpv.com/news/oxford-pv-sets-world-recordperovskite-solar-cell (accessed 23 August 2020).

6) Advanced Science News, https://www.advancedsciencenews.com/ almost-40-conversion-efficiency-predicted-in-new-perovskite-solarcell/ (accessed 23 August 2020).
7) Kaltenbrunner, M., White, M., Głowacki, E., Sekitani, T., Someya, T., Sariciftci, N., and Bauer, S.: Ultrathin and Lightweight Organic Solar Cells with High Flexibility, Nature Commun., 3, 770 (2012), p. 7.

8) Chang, N., Ho-Baillie, A. Y., Vak, D., Gao, M., Green, M., and Egan, R.: Manufacturing Cost and Market Potential Analysis of Demonstrated Roll-to-roll Perovskite Photovoltaic Cell Processes, Solar Energy Mater. Solar Cells, 174 (2018), pp. 314-324.

9) Miyazawa, Y., Ikegami, M., Chen, H., Ohshima, T., Imaizumi, M., Hirose, K., and Miyasaka, T.: Tolerance of Perovskite Solar Cell to High-energy Particle Irradiations in Space Environment, iScience, 2 (2018), pp. 148-155.

10) Wang, Q., Chen, B., Liu, Y., Deng, Y., Bai, Y., Donga, Q., and Huang, J.: Scaling Behavior of Moisture-induced Grain Degradation in Polycrystalline Hybrid Perovskite Thin Films, Energy Environ. Sci., 10 (2017), pp. 516-522.

11) Song, Z., Abate, A., Watthage, S. C., Liyanage, G. K., Phillips, A. B., Steiner, U., Graetzel, M., and Heben, M. J.: Perovskite Solar Cell Stability in Humid Air: Partially Reversible Phase Transitions in the $\mathrm{PbI}_{2}-\mathrm{CH}_{3} \mathrm{NH}_{3} \mathrm{I}-\mathrm{H}_{2} \mathrm{O}$ System, Adv. Energy Materials, 6, 19 (2016), 1600846.

12) Yang, J., Bao, Q., Shen, L., and Ding, L.: Potential Applications for Perovskite Solar Cells in Space, Nano Energy, 76 (2020), 105019.

13) Sheikh, A. D., Munir, R., Haque, M. A., Bera, A., Hu, W., Shaikh, P., Amassian, A., and Wu, T.: Effects of High Temperature and Thermal Cycling on the Performance of Perovskite Solar Cells: Acceleration of Charge Recombination and Deterioration of Charge Extraction, ACS Appl. Mater. Interfaces, 9, 40 (2017), pp. 35018-35029.

14) Lee, S.-W., Kim, S., Bae, S., Cho, K., Chung, T., Mundt, L. E., Lee, S., Park, S., Park, H., Schubert, M. C., Glunz, S. W., Ko, Y., Jun, Y., Kang, Y., Lee, H.-S., and Kim, D.: UV Degradation and Recovery of Perovskite Solar Cells, Scientific Reports, 6 (2016), 38150.

15) Guter, W., Dunzer, F., Ebel, L., Hillerich, K., Köstler, W., Kubera, T., Meusel, M., Postels, B., and Wächter, C.: Space Solar Cells - 3 G30 and Next Generation Radiation Hard Products, E3S Web of Conferences, Vol. 16, 03005, 2017.

16) Cai, M., Wu, Y., Chen, H., Yang, X., Qiang, Y., and Han, L.: Cost-Performance Analysis of Perovskite Solar Modules, Advanced Science, 4 (2017), 1600269.

17) Kaltenbrunner, M., Adam, G., Głowacki, E., Drack, M., Schwödiauer, R., Leonat, L., Apaydin, D., Groiss, H., Scharber, M., White, M., Sariciftci, N., and Bauer, S.: Flexible High Power-per-weight Perovskite Solar Cells with Chromium Oxide-metal Contacts for Improved Stability in Air, Nature Materials, 14 (2015), pp. 1032-1039.

18) Salim, T., Sun, S., Abe, Y., Krishna, A., Grimsdalea, A. C., and Lam, Y. M.: Perovskite-based Solar Cells: Impact of Morphology and Device Architecture on Device Performance, J. Mater. Chem. A, 3, 17 (2015), pp. 8943-8969.

19) Pitchaiya, S., Natarajan, M., Santhanam, A., Asokan, V., Yuvapragasam, A., Ramakrishnan, V. M., Palanisamy, S. E., Sundaram, S., and Velauthapillai, D.: A Review on the Classification of Organic/inorganic/carbonaceous Hole Transporting Materials for Perovskite Solar Cell Application, Arabian J. Chemistry, 13 (2020), pp. 2526-2557.

20) Huang, L., Hu, Z., Xu, J., Zhang, K., Zhang, J., Zhang, J., and Zhu, Y.: Efficient and Stable Planar Perovskite Solar Cells with a Non-hygroscopic Small Molecule Oxidant Doped Hole Transport Layer, Electrochimica Acta, 196 (2016), pp. 328-336.

21) Hawash, Z., Ono, L. K., and Qi, Y.: Recent Advances in SpiroMeOTAD Hole Transport Material and Its Applications in OrganicInorganic Halide Perovskite Solar Cells, Advanced Materials Interfaces, 5, 1 (2018), 1700623.

22) Bach, U., Lupo, D., Comte, P., Moser, J., Weissortel, F., Salbeck, J., Spreitzer, H., and Gratzel, M.: Solid-state Dye-sensitized Mesoporous TiO2 Solar Cells with High Photon-to-electron Conversion Efficiencies, Nature, 395 (1998), pp. 583-585.

23) Christians, J., Fung, R., and Kamat, P.: An Inorganic Hole Conductor for Organo-lead Halide Perovskite Solar Cells Improved Hole Conductivity with Copper Iodide, J. Am. Chem. Soc., 136 (2014), pp. 758-764.

24) Chavhan, S., Miguel, O., Grande, H.-J., Gonzalez-Pedro, V., Sanchez, R., Barea, E., Mora-Sero, I., and Tena-Zaera, R.: Organo-metal Halide 
Perovskite-based Solar Cells with CuSCN as the Inorganic Hole Selective Contact, J. Mater. Chem. A, 2 (2014), pp. 12754-12760.

25) Ito, S., Tanaka, S., Vahlman, H., Nishino, H., Manabe, K., and Lund, P.: Carbon-Double-Bond-Free Printed Solar Cells from $\mathrm{TiO}_{2} /$ $\mathrm{CH}_{3} \mathrm{NH}_{3} \mathrm{PbI}_{3} / \mathrm{CuSCN} / \mathrm{Au}$ : Structural Control and Photoaging Effects, Chem. Phys. Chem., 15, 6 (2014), pp. 1194-1200.

26) Zhao, R., Yan, B., Yang, Y., Kim, T., and Amassian, A.: Solutionprocessed Inorganic Copper(I) Thiocyanate (CuSCN) Hole Transporting Layers for Efficient p-i-n Perovskite Solar Cells, J. Mater. Chem. A, 3 (2015), pp. 20554-20559.

27) Yang, Y., Xiao, J., Wei, H., Zhu, L., Li, D., Luo, Y., Wu, H., and Meng, Q.: An All-carbon Counter Electrode for Highly Efficient Hole Conductor-free Organo-metal Perovskite Solar Cells, RSC Adv., 4 (2014), pp. 52825-52830.

28) Zhang, F., Yang, X., Cheng, M., Wang, W., and Sun, L.: Boosting the Efficiency and the Stability of Low Cost Perovskite Solar Cells by Using CuPc Nanorods as Hole Transport Material and Carbon as Counter Electrode, Nano Energy, 20 (2016), pp. 108-116.

29) Sigma-Aldrich: https://www.sigmaaldrich.com/united-states.html (accessed 30 September 2020).

30) Cardinaletti, I., Vangervena, T., Nagelsa, S., Cornelissend, R., Schreursa, D., Hrubya, J., Vodnikd, J., Devisschera, D., Kestersa, J., D'Haena, J., Franquete, A., Spampinatoe, V., Conarde, T., Maes, W., Deferme, W., and Manca, J.: Organic and Perovskite Solar Cells for Space Applications, Solar Energy Materials and Solar Cells, 182 (2018), pp. 121-127.

31) Reb, L., Böhmer, M., Predeschly, B., Grott, S., Weindl, C., Ivandekic, G., Guo, R., Dreißigacker, C., Gernhäuser, R., Meyer, A., and MüllerBuschbaum, P.: Perovskite and Organic Solar Cells on a Rocket Flight, Joule, 4 (2020), pp. 1880-1892.

32) Herrick, K.: Building Solar Panels in Space Might Be as Easy as Clicking Print, https://www.nasa.gov/feature/glenn/2019/building-solarpanels-in-space-might-be-as-easy-as-clicking-print (accessed 1 July 2021).

33) Funase, R., Takei, E., Nakamura, Y., Nagai, M., Enokuchi, A., Yuliang, C., Nakada, K., Nojiri, Y., Sasaki, F., Funane, T., Eishima, T., and Nakasuka, S.: Technology Demonstration on University of Tokyo's Pico-satellite "XI-V" and Its Effective Operation Result Using Ground Station Network, Acta Astronautica, 61 (2007), pp. 707-711.

34) Morioka, C., Shimazaki, K., Kawakita, S., Imaizumi, M., Yamaguchi, H., Takamoto, T., Sato, S., Ohshima, T., Nakamura, Y., Hirako, K., and Takahashi, M.: First Flight Demonstration of Film-laminated InGaP/GaAs and CIGS Thin Film Solar Cells by JAXA's Small Satellite in LEO, Progress in Photovoltaics: Research and Applications, 19 (2011), pp. 825-833.
35) Okada, K., Seri, Y., Shibagaki, R., Masui, H., and Cho, M.: Ground Tests and In-Orbit Results for the Horyu-II Nanosatellite Power System, Trans. JSASS Aerospace Technology Japan, 12 (2014), pp. Tf_49-Tf_56.

36) Matteocci, F., Cinà, L., Lamanna, E., Cacovich, S., Divitini, G., Midgley, P. A., Ducati, C., and Carlo, A. D.: Encapsulation for Longterm Stability Enhancement of Perovskite Solar Cells Fabio, Nano Energy, 30 (2016), pp. 162-172.

37) Cheacharoen, R., Rolston, N., Harwood, D., Bush, K. A., Dauskardt, R. H., and McGehee, M. D.: Design and Understanding of Encapsulated Perovskite Solar Cells to Withstand Temperature Cycling, Energy Environ. Sci., 11 (2018), pp. 144-150.

38) Christians, J. A., Schulz, P., Tinkham, J. S., Schloemer, T. H., Harvey, S. P., Tremolet de Villers, B. J., Sellinger, A., Berry, J. J., and Luther, J. M.: Tailored Interfaces of Unencapsulated Perovskite Solar Cells for $>1,000$ h Operational Stability, Nat. Nature Energy, 3 (2018), pp. $68-74$.

39) Galarynk, M.: Understanding Boxplots, https://towardsdatascience. com/understanding-boxplots-5e2df7bcbd51 (accessed 30 June 2021).

40) Christians, J., Manser, J., and Kamat, P.: Best Practices in Perovskite Solar Cell Efficiency Measurements. Avoiding the Error of Making Bad Cells Look Good, J. Phys. Chem. Lett., 6 (2015), pp. 852-857.

41) Tindo Solar: https://www.tindosolar.com.au/learn-more/temperaturecoefficient/\#: : :text=As\%20a\%20solar\%20panel\%20increases,every\% 20degree\%20the\%20temperature\%20rises (accessed 7 September 2020)

42) Aho, A., Isoaho, R., Tukiainen, A., Polojarvi, V., Aho, T., Raappana, M., and Guina, M.: Temperature Coefficients for GaInP/GaAs/ GaInNAsSb Solar Cells, AIP Conference Proceedings, Vol. 1679, 0500012015.

43) Yang, J., Hong, Q., Yuan, Z., Xu, R., Guo, X., Xiong, S., Liu, X., Braun, S., Li, Y., Tang, J., Duan, C., Fahlman, M., and Bao, Q.: Unraveling Photostability of Mixed Cation Perovskite Films in Extreme Environment, Advanced Optical Materials, 6 (2018), 1800262.

44) Roghabadi, F. A., Fumani, N. M. R., Alidaei, M., Ahmadi, V., and Sadrameli, S. M.: High Power UV-Light Irradiation as a New Method for Defect Passivation in Degraded Perovskite Solar Cells to Recover and Enhance the Performance, Scientific Reports, 9 (2019), 9448.

45) Hadadian, M., Smått, J.-H., and Correa-Baena, J.-P.: The Role of Carbon-based Materials in Enhancing the Stability of Perovskite Solar Cells, Energy Environ. Sci., 13 (2020), pp. 1377-1407.

Yasuhiro Kawakatsu Editor-in-Chief 